\title{
Экспертиза
}

ХОДИНОВА Ольга Сергеевна - аспирант Дипломатической академии Министерства иностранных дел РФ (119021, Россия, г. Москва, ул. Остоженка, 53/2, стр. 1; olga.khodinova@gmail.com)

\section{ИНТЕРКУЛЬТУРАЛИЗМ КАК НОВАЯ СТРАТЕГИЯ ВКЛЮЧЕНИЯ МИГРАНТОВ В ЕВРОПЕЙСКУЮ НАЦИЮ (НА ПРИМЕРЕ ФРАНЦИИ)}

\begin{abstract}
Аннотация. Статья посвящена анализу новейших тенденций в осмыслении меняющейся стратегии приема мигрантов странами - членами Европейского союза. В статье анализируется смена парадигмы мультикультурализма на интеркультурализм в качестве более эффективной стратегии интеграции иноэтничных мусульман в европейское общество. На примере Франции автор показывает, что интеркультурализм становится «третьим путем» для государств, стоящих перед трудным выбором между возвратом к ассимиляции и постмультикультуралистскими поисками.
\end{abstract}

Ключевые слова: Франция, Европейский союз, миграционная политика, мультикультурализм, интеркультурализм, идентичность, мигранты

$\mathrm{H}$ а протяжении трех последних лет после пика миграционного кризиса в 2015 г. Европейский союз пытается выработать единую для всех странчленов политику приема иноэтничных иммигрантов - выходцев с Ближнего Востока и из Северной Африки, в большинстве своем - мусульман.

Еще за несколько лет до миграционного кризиса европейские власти на самом высоком уровне заявили о провале политики мультикультурализма: в 2010 г. это сделали канцлер ФРГ Ангела Меркель и премьер-министр Великобритании Дэвид Кэмерон, в 2011 г. - президент Франции Николя Саркози. Критическое отношение к этому концепту нашло практическое выражение в законотворческой деятельности органов власти некоторых западноевропейских стран: в частности, в виде ограничения прав отдельных этнических групп мигрантов, основанных на культурно-религиозных отличиях (запрет на ношение закрывающей лицо одежды в общественных местах, на строительство минаретов и т.п.). Таким образом, усиление этнокультурного многообразия обернулось на практике не следованием девизу: «Пуст расцветают все цветы (в смысле - культуры)», а маргинализацией приезжих, геттоизацией общин, превращением территорий, населенных преимущественно мигрантами, в субкультурные анклавы (как это произошло с пригородом Парижа Сен-Дени, куда полицейские не рискуют заглядывать поодиночке). Итог тревожен: нарастание межэтнической напряженности и атомизация европейских обществ.

Как это часто бывает, практика догнала теорию намного позже, ведь об отсутствии у концепции мультикультурализма интеграционного потенциала эксперты заговорили задолго до громких заявлений первых лиц Германии, Великобритании и Франции 1 . В 2008 г. Совет Европы выпустил так называемую Белую книгу по межкультурному диалогу «Жить вместе в равном достоинстве», в которой предполагалось обеспечивать бесконфликтное сосуществование различных культур с опорой на либеральные концепции «культурного

\footnotetext{
1 Кстати, само заявление Н. Саркози о провале мультикультурализма вызывает удивление, т.к. политика мультикультурализма в принципе противоречит Конституции Французской Республики, где все граждане объявлены равными и отрицается какой-либо коммунитаризм.
} 
разнообразия» ${ }^{1}$ и провозглашался переход к новой «межкультурной системе» (в английском варианте - Emerging Interculturalist Paradigm). Тогда же, в 2008 г., в ЕС был объявлен Европейский год межкультурного диалога. В 2009 г. ЮНЕСКО опубликовало доклад «Инвестирование в культурное разнообразие и диалог между культурами», в котором межкультурный диалог позиционировался как выход из тупика, в который завел либеральные европейские общества концепт мультикультурализма.

Итак, в чем же заключается для европейских наций преимущество интеркультурализма перед мультикультурализмом как моделью управления культурным разнообразием?

Концепция мультикультурализма начала обретать популярность в Нидерландах, Великобритании, Бельгии, Германии, Швеции и других странах Западной Европы в 1980-х гг. Мультикультурализм стал попыткой поиска новых возможностей развития национальных обществ в ситуации растущей культурной плюральности.

Ключевое для концепции понятие - община. Мультикультурным авторы концепции называют общество, включающее в себя две или более культурные общины [Parekh 2002: 6], «каждая из которых обладает более или менее специфичным пониманием того, что есть благо, и имеет свою особую историю, социальную структуру, традиции, потребности и устремления» [Parekh 1999: 449]. Конечная цель мультикультурализма - искоренение дискриминации и достижение равенства различного рода меньшинств с национальным большинством с признанием при этом права на отличие.

Идеологией, которая способна прийти на смену мультикультурализму, многие исследователи называют межкультурный диалог, или интеркультурализм. Как политическая концепция он возникает в ответ на либеральную критику мультикультуралистских принципов. В отличие от мультикультурализма, призванного защищать статичные культуры, интеркультурализм - это «открытый динамичный процесс преобразования социальных контуров и культуры общества путем диалога и комплементарного интеркультурного взаимодействия» [Куропятник, Куропятник 2018: 254], процесс гибридизации культур. В основе интеркультурализма лежит идея многомерности различий вместо их репрезентации на основе концептов расы, культуры, языка или религии. Интеркультурализм предполагает изменение модели социальной интеграции и характера социальных отношений за счет смещения акцентов с отношений типа «государство - группа» на отношения между индивидами и «государство - индивид». Интеркультурализм с уровня государства переходит на уровень муниципалитета пропорционально укрупнению, своего рода детализации фокуса внимания с уровня социальной группы до уровня конкретного человека.

Первыми обозначили новый подход британские исследователи Ф. Вуд, Ш. Ландри и Дж. Блумфилд в 2006 г. в работе «Культурное многообразие в Великобритании: методическое руководство по кросс-культурному сотрудничеству». Она была посвящена раскрытию потенциала культурного многообразия и поискам способа наиболее эффективного управления им - через обмен и взаимодействие между различными группами [Борисова 2014]. Центральной площадкой для таких взаимодействий был назван город. Именно в этой работе впервые провозглашалось, что наличие меньшинств, их творческий потенциал и своеобычность - не проблема, а преимущество, ресурс экономического, социального и культурного развития города, региона, страны. Исходя из этих

\footnotetext{
1 Paper on Intercultural Dialogue «Living Together as Equals in Dignity». URL: http://www.coe.int/t/dg4/ intercultural/source/white\%20paper_final_revised_en.pdf (accessed 05.12.2018).
} 
позиций, Европейская комиссия, Совет Европы и ЮНЕСКО сочли интеркультурализм перспективным направлением, основанным на принципе уважения человеческого достоинства, фундаментальных европейских ценностей, а также общего для всех мирового наследия и культурного разнообразия 1 .

В теоретических подходах к пониманию интеркультурализма выявляются существенные разногласия. Его, в частности, рассматривают и как альтернативу мультикультурализму, своего рода новый взгляд на усиление социальной сплоченности [Bello, Bloom 2017: 6], и как концепт эпохи постмультикультурализма [Bradley 2013: 6], и как своего рода «третий путь» для тех обществ, которые встали перед выбором между мультикультурализмом и ассимиляцией [Grillo 2016]. При этом один из создателей концепции Т. Кэнтл в своей книге «Интеркультурализм: новая эра сплоченности и многообразия» пишет, что концепция «сплоченности общин» стала переходным этапом от мультикультурализма к интеркультурализму [Cantle 2012: 90]. Сопоставляя эти подходы, один из авторов концепции мультикультурализма канадский ученый Ч. Тэйлор приходит к выводу, что для европейских стран более пригоден как раз интеркультурализм [Taylor 2012]. Существует и другая точка зрения, согласно которой мультикультурализм публично принесли в жертву общественному мнению, чтобы лишить аргументов правые националистические партии и движения, и произошла лишь замена понятий, без изменения сущностных характеристик подхода [Bradley 2013: 9].

Вслед за немногими отечественными исследователями, занимающимися проблемами интеркультурализма [Куропятник, Куропятник 2018; ТабаринцеваРоманова, Поспелова 2018], мы разграничиваем два подхода и оцениваем интеркультурализм как попытку создать принципиально новую модель построения межкультурных отношений. С этих позиций рассмотрим текущую социально-политическую ситуацию во Франции и перспективы интеркультурализма в ней.

Рассуждая о причинах провала мультикультурализма, К. Йоппке указывает в качестве одной из главных слишком либеральную миграционную политику европейских государств в 1950-х гг.: «Послевоенные западные государства не стали требовать от мигрантов отказа от родной культуры в качестве "платы за вход”. Повторяя мантру: “интеграция - не ассимиляция”, европейцы оставили культурную целостность иммигрантов нетронутой» [Joppke 2010: 51]. Для Французской республики, напротив, всегда была характерна насильственная монокультурность, прием мигрантов с середины XX в. происходил по формуле: «во Франции все французы»; «для французов интеграция человека может быть признана успешной лишь в том случае, если он разделяет их принципы в том, что касается личной свободы, равенства мужчин и женщин, братства, светского общества и т.д.» ${ }^{2}$ С начала нулевых годов для встраивания во французское общество каждому приезжему приходится подписывать с государством «контракт приема и интеграции» $(C A I)$ с обязательством придерживаться республиканских ценностей.

За почти 70 лет проведения миграционной политики Франция успела опробовать три стратегии приема иммигрантов: ассимиляцию, адаптацию, интеграцию. Элементы мультикультурализма в законодательстве страны присутствуют,

\footnotetext{
${ }^{1}$ Всемирный доклад ЮНЕСКО: Инвестирование в культурное разнообразие и диалог между культурами. Доступ: http://unesdoc.unesco.org/images/0018/001852/185202r.pdf (проверено 05.12.2018).

2 Echec des politiques d'intégration : nous payons le prix de 30 ans d'erreur de diagnostic. Malika SorelSutter. Publie 11 Février 2013. Доступ: https://www.atlantico.fr/decryptage/635325/integration--non-unpeuple-ne-doit-pas-accommoder-ses-principes-et-valeurs-au-benefice-des-populations-immigrees-malikasorel (проверено 05.12.2018).
} 
но четко не выделяются. Так, при запрете ношения закрывающей лицо одежды в государственных образовательных учреждениях и общественных местах разрешен допуск священнослужителей различных конфессий в больницы, для детей-мусульман в школьных столовых предусмотрено особое меню, а МВД сотрудничает с лидерами религиозных общин по таким вопросам, как, например, строительство культовых сооружений.

Немаловажный аспект мультикультурализма - позитивная дискриминация - подвергся бурному обсуждению в политических и общественных кругах Франции непосредственно перед президентскими выборами 2007 г., когда президент Н. Саркози заговорил о переформатировании модели интеграции и переходе от массовой иммиграции к выборочной. Многие эксперты подозревают Саркози в намеренном популизме, ведь идеология «позитивной дискриминации» противоречит ст. 6 Декларации прав человека и гражданина 1789 г.: «Все граждане равны перед законом и поэтому имеют равный доступ ко всем постам, публичным должностям и занятиям сообразно их способностям и без каких-либо иных различий, кроме тех, что обусловлены их добродетелями и способностями» 1 . При этом и среди сторонников, и среди противников «позитивной дискриминации» оказалось много видных политиков как республиканского, так и регионального, и муниципального уровней вне зависимости от партийной принадлежности. Кандидат в президенты от социалистов и глава крупного региона Пуату-Шаранта Сеголен Руаяль и вовсе предложила провести референдум по правам меньшинств и по поводу введения рабочих и учебных квот [Sorel 2007].

В итоге в марте 2006 г. правительство приняло закон «О равенстве шансов» 2 , но он не был до конца проработан: в качестве одной из мер помощи молодежи, которая сталкивается с трудностями при приеме на работу, был прописан «договор первого найма», позволявший работодателю в течение первых 2 лет увольнять новых сотрудников в возрасте до 26 лет без объяснения причин. Это послужило поводом для массовых протестов, после которых в новую редакцию закона были внесены изменения, касающиеся трудоустройства лишь тех молодых людей, которые испытывают трудности в поисках работы из-за низкого образовательного уровня ${ }^{3}$.

Последняя по времени новация в сфере интеграции на национальном уровне принадлежит социалистам: в 2013 г. советник президента Ф. Олланда Т. Тюо разработал концепцию «инклюзивного общества» 4 . За 8 месяцев рабочие группы подготовили поистине революционные предложения, среди которых были: полная легализация незаконных иммигрантов; упрощение процедуры принятия гражданства; разрешение публичных молитв; «лучшая интеграция ислама, которому нужно дать место большой религии» [Tribalat 2013: 237-238]. Последний пункт представляет собой продолжение идеи Н. Саркози о необходимости развития «французского ислама» путем его институционализации - создания в светском государстве (курсив мой. - O.X.) Совета мусульманских культов для взращивания «авторитетного руководства, представляющего инте-

1 Déclaration des Droits de l'Homme et du Citoyen de 1789. Доступ: https://www.legifrance.gouv. fr/Droit-francais/Constitution/Declaration-des-Droits-de-1-Homme-et-du-Citoyen-de-1789 (проверено $05.12 .2018)$.

2 LOI n² 2006-396 du 31 mars 2006 pour l'égalité des chances (1). Доступ:: https://www.legifrance.gouv.fr/ affichTexte.do? cidTexte $=$ JORFTEXT000000268539\&dateTexte $=\&$ categorieLien $=$ id $($ проверено 05.12.2018).

3 Под давлением профсоюзов во Франции отменен «договор первого найма». Доступ: http://palm. newsru.com/world/10apr2006/france.html (проверено 05.12.2018).

4 La grand nation : pour une société inclusive. Rapport au Premier ministre sur la refondation des politiques d'intégration. 1er février 2013. Доступ: http://www.ladocumentationfrancaise.fr/var/storage/ rapports-publics/134000099.pdf (проверено 05.12.2018). 
ресы исламского сообщества Франции» [Федоров 2015: 62]. Разумеется, эти инициативы, идущие вразрез с республиканскими принципами, были встречены в обществе крайне негативно, и от них было решено отказаться. При этом через два года, в 2015 г., после атаки на журнал карикатур Charlie Hebdo был создан «Союз французских мусульманских демократов», что говорит о стремлении мусульман во Франции объединиться для защиты своих прав на государственном уровне и вместе с тем ставит под сомнение сами основы французской государственности.

Современные законодательные акты позволяют трактовать текущее направление миграционной политики Франции как очевидно ассимиляционное. Авторы последнего законопроекта, поступившего на рассмотрение Национального собрания в начале 2018 г., предлагают, например, сократить с 14 до 6 месяцев срок рассмотрения просьб об убежище, но одновременно упростить процедуру выдворения из Франции. Также предлагается продлевать срок содержания под стражей нелегалов, которым грозит выдворение 1 . Президент Э. Макрон, который во время предвыборной кампании заявлял, что миграция - шанс для Франции, за счет чего получил поддержку около 90\% экспатов, теперь заявляет, что законопроект министра внутренних дел Ж. Коллона призван как можно быстрее выдворять из страны тех, кому в убежище отказали, потому что «Европа столкнулась с беспрецедентным потоком мигрантов, который не прекращается, а Франция не может принять всех бедных» ${ }^{2}$. Впрочем, законодательную инициативу Ж. Коллона критикуют правозащитники, оппозиция и даже некоторые представители парламентского большинства из партии «Вперед, Республика». Примечательно, что левые критикуют его за излишнюю мягкость, а правые - за недостаточную жесткость. «Республиканцы» считают, например, что нужно ввести ежегодные квоты на прием мигрантов и беженцев и ограничить воссоединение семей.

Таким образом, в настоящий момент во французском законодательстве прописана «республиканская модель» приема мигрантов по типу ассимиляции, вместе с тем присутствуют и элементы мультикультурализма. Интеркультурализм может стать для Франции решением многолетней проблемы поиска адекватной современным реалиям модели приема иммигрантов. Так, город Лион с 2008 г. участвует в совместной программе Европейской комиссии и Совета Европы «Межкультурные города». В октябре 2018 г. он принял неформальную встречу представителей МВД 6 стран ЕС: Франции, Германии, Италии, Польши, Великобритании и Испании ${ }^{3}$. Обсуждалась общеевропейская позиция по борьбе с миграционным кризисом. Глава МВД Франции Э. Филипп заявил, что проблему невозможно решить на национальном уровне.

Пока ЕС ищет единое для всех стран решение, интеркультурализм предлагает работать на муниципальном уровне. В том же Лионе, который подключился к программе из 14 городов (включающей даже российский Ижевск), уже несколько лет существует мусульманское гетто - район Магнетт. Такие же гетто существуют в Париже, Марселе, Бордо, да и многих других городах Франции и ее соседей по Евросоюзу. Смещение акцента политики интеграции на уровень местного самоуправления может позволить решать проблемы взаимодействия и взаимопроникновения различных культур последовательно. Французы,

1 За что во Франции критикуют проект закона об иммиграции? Доступ: http://ru.rfi.fr/ frantsiya/20180416-vo-frantsii-proekt-zakona-ob-immigratsii-stal-predmetom-zharkikh-sporov (проверено 05.12.2018).

2 Там же.

3 В Лионе обсуждают миграционный кризис. Доступ: https://ru.euronews.com/2018/10/09/lyonmeeting-interior-ministry (проверено 05.12.2018). 
похоже, к этому готовы. Это, в частности, подтверждает статистика межнациональных браков: 27\% брачных союзов граждане Франции заключают с иностранцами, в основном - с выходцами из Алжира, Марокко и Туниса 1.

Формирование европейской модели интеркультурализма происходит, с одной стороны, в условиях «усталости» от расширения границ Евросоюза, с другой - в ситуации роста популярности идеи национального государства [Куропятник, Куропятник 2018: 256]. Таким образом, модель интеркультурализма в практическом его выражении разработана не до конца. Судя по жаркой дискуссии в авторитетном журнале «Сравнительные исследования миграции» (Comparative Migration Studies), развернувшейся весной 2018 г. между апологетом мультикультурализма Т. Модудом [Modood 2018] и теми, кто отстаивает интеркультурализм [Joppke 2018], в среднесрочной перспективе концепт будет оставаться одной из главных тем европейских политологических исследований и практических экспериментов.

\section{Список литературы}

Борисова М.В. 2014. Теория и практики интеркультурализма в современном мире. - Проблемы истории, филологии, культуры. № 2(44). С. 367-374.

Куропятник А.И., Куропятник М.С. 2018. Интеркультурализм: постмультикультуральный дискурс социальной интеграции. - Вестник РУДН. Сер. Социология. Т. 18. № 2. С. 250-261.

Табаринцева-Романова К.М., Поспелова Т.В. 2018. Межкультурный диалог как инструмент публичной дипломатии Европейского союза. - Асимметрии региональных интеграционных проектов ХХІ века: монография (под ред. В.И. Михайленко). Екатеринбург: Изд-во Уральского ун-та. С. 127-141.

Федоров С.М. 2015. Франция. Трудные поиски обновления «республиканской модели» интеграции иммигрантов. - Миграционные проблемы в Европе и пути их решения. М.: Изд-во Института Европы РАН. С. 54-67.

Bello V., Bloom T. 2017. Interculturalism in Times of Crisis. - International Migration. Vol. 55. No. 2. P. 5-9.

Bradley W. 2013. Is There a Post-multiculturalism?19 p. URL: http://afrasia.ryukoku. ac.jp/english/publication/upfile/WP19.pdf (accessed 05.12.2018).

Cantle T. 2012. Interculturalism: The New Era of Cohesion and Diversity. Springer. 249 p.

Grillo R. 2016. But What Is Interculturalism? URL: https://www.researchgate.net/ publication/311650122_But_What_IS_Interculturalism (accessed 05.12.2018).

Joppke C. 2010. Minority Rights for Immigrants? Multiculturalism versus Antidiscrimination. - Israel Law Review. Vol. 43. No. 1. P. 49-66.

Joppke C. 2018. War of Words: Interculturalism v. Multiculturalism. - Comparative Migration Studies. Vol. 6. No. 1. Р. 11. Доступ: https://www.ncbi.nlm.nih.gov/pmc/ articles/PMC5956050/ (accessed 05.12.2018).

Modood T. 2018. Interculturalism: Not a New Policy Paradigm. - Comparative Migration Studies. Vol. 6. No. 1. P. 22. Доступ: https://www.ncbi.nlm.nih.gov/pmc/ articles/РMC6006275/ (проверено 05.12.2018)

Parekh B. 1999. Common Citizenship in Multicultural Societies. - The Commonwealth Journal of International Affairs. Vol. 88. No. 351. P. 449-460.

Parekh B. 2002. Rethinking Multiculturalism: Cultural Diversity and Political Theory. Harvard University Press. 400 p.

Sorel M. 2007. Le puzzle de l’intégration: les pièces qui vous manquent. Paris. 271 p.

1 Французы выбирают иностранцев: статистика смешанных браков. Доступ: http://ru.rfi.fr/ frantsiya/20170314-frantsuzy-vybirayut-suprugov-inostrantsev-statistika-smeshannykh-brakov (проверено 05.12.2018). 
Taylor C. 2012. Interculturalism or Multiculturalism? - Philosophy and Social Criticism. Vol. 38. Nos. 4-5. P. 413-423.

Tribalat M. 2013. Assimilation: la fin du modèle français. Paris. 349 p.

KHODINOVA OI'ga Sergeevna, postgraduate student at the Diplomatic Academy of the Russian Foreign Ministry (bld. 1, 53/2 Ostozhenka St, Moscow, Russia, 119021; olga.khodinova@gmail.com)

\title{
INTERCULTURALISM: THE NEW STRATEGY OF MIGRANT INCLUSION IN THE EUROPEAN NATION (A CASE STUDY OF FRANCE)
}

\begin{abstract}
The article analyzes the most current trends in rethinking the EU strategy of admitting foreign migrants. Amid the growing cultural and religious diversity that has been triggered by the migration crisis, the European nations and governments realize the need to manage effectively this situation. Having abandoned the concept of multiculturalism in 2010-2011, Germany, the United Kingdom and France - the EU key-players, are in search of a new model. Interculturalism, the fundamental principles of which were formulated in European legislature in the late 2000s, presupposes the convergence of different cultures on the base of respect for the individual. From the point of view of managing cultural diversity, the author concludes that interculturalism as a policy proves to be far more effective, while it suggests working with different culture groups, primarily at the level of municipalities, and its effective implementation can be applied nationwide. This case study of France proves that amid the migration crisis, interculturalism is on its way to become the third solution for countries facing a difficult choice between a return to assimilation tactics and a search for a post-multiculturalism strategy. However, the concept of interculturalism has not yet been defined which leaves room for theoretical apprehension of the concept. Keywords: France, European Union, migration policy, multiculturalism, interculturalism, identity, migrants
\end{abstract}

ПИВОВАРОВА Марина Борисовна - магистр социологического факультета Московского государственного университета им. М.В. Ломоносова (119234, Россия, г. Москва, ул. Ленинские Горы, 1, cmp.33;mp1995@mail.ru)

\section{ГОСУДАРСТВЕННОЕ РЕГУЛИРОВАНИЕ НАУКИ В ВЫСШИХ УЧЕБНЫХ ЗАВЕДЕНИЯХ}

Аннотация. Трансформация роли научного знания в обществе, нарастание процессов глобализации, а также формирование единого образовательного пространства привело к возрастанию роли науки в развитии государства. Перед современной наукой стоят задачи национального масштаба, направленные на обеспечение национальных приоритетов посредством грамотного государственного регулирования. Ключевые слова: государственное регулирование, наука информационного общества, роль научных проектов в инновационной политике

\footnotetext{
Современная инновационная политика Российской Федерации, несмотря на нестабильность и кризис, направлена на развитие технического и экономического потенциала страны, а также обеспечение конкурентоспособности производимых товаров и услуг на мировой арене. Научная деятельность, в свою очередь, следуя основным направлениям развития государственной политики, должна гарантировать повышение уровня благосостояния населения и становление нашей страны как одного из лидеров на мировой арене. Об этом говорится в Стратегии инновационного развития Российской Федерации, согласно
} 